\title{
Termoplásticos e termoendurecíveis
}

Analisa-se de forma esquemática a classificação convencional dos Polímeros e descrevem-se as aplicaçð̄es industriais dos de maior importância em cada classe. Referem-se de forma breve novos tipos de estruturas poliméricas cuja classificação em qualquer das classes tradicionais tem suscitado polémica.

\section{Introdução}

A classificação dos Polímeros em duas grandes classes tipológicas designadamente Termoplásticos e Termoendurecíveis pode ser feita de forma esquemática com base no tipo de estrutura química do polímero e processo de transformação que lhe é aplicável:

\section{QUADRO 1}

\begin{tabular}{l|c|c}
\hline & $\begin{array}{c}\text { ESTRUTURA } \\
\text { MOLECULAR }\end{array}$ & $\begin{array}{c}\text { PROCESSO DE } \\
\text { TRANSFORMAÇÃO }\end{array}$ \\
\hline Termoplásticos & $\begin{array}{c}\text { Predominantemente } \\
\text { Linear }\end{array}$ & $\begin{array}{c}\text { FíSICO } \\
\text { (De forma geral por } \\
\text { amolecimento) }\end{array}$ \\
\hline Termoendurecíveis & Ramificada & $\begin{array}{c}\text { QUíMICO } \\
\text { (A partir de monómeros } \\
\text { ou prepolimeros) }\end{array}$ \\
\hline
\end{tabular}

A designação Termoendurecíveis, se bem que mais correcta que designaçð̃es como Termoendurecidos ou Termorígidos não exprime o aspecto de a transformação se dar com reacção química, nem o facto essencial de a estrutura química do polimero se alterar significativamente durante a transformação.

É nestas circunstâncias que surge a designação de Polímeros Reactivos, que tem vindo a ganhar aceitação.

\section{Aplicações Actuais e Futuras}

Para alguns polímeros com importância industrial são indicados no QUADRO 2, a sigla geralmente utilizada, aplicaçð̃es típicas e potencialidades de utilização (área em desenvolvimento).

QUADRO 2

Polimero

Polietileno

Polipropileno

Policloreto de vinilo

Poliesteres insaturados Poliuretanos

Poliacrilonitrilo Ureia Formaldeido

\section{Símbolo Aplicações}

PE Filme, tubos, isolamentos de cabos

PP Componentes injectados, fibras, tecidos

PVC Isolamento, tubos, peças injectadas, napas

UP Plásticos reforçados, tintas, botððes

PU Espumas, tintas, colas, revestimentos têxteis

PAN Fibras têxteis

UF Colas, electrotecnia

\section{Polímeros auto-reforçados e polímeros "IPN"}

Recentemente surgiram polímeros com novos tipos de estrutura, difíceis de classificar quer como termoplásticos quer como termoendurecíveis.

A designação de "auto-reforçados" surgiu por analogia com os materiais compósitos com fibras, e tem sido predominantemente usada para designar polímeros (Termoplásticos e Termoendurecíveis) com macro cristalitos de orientação preferencial de que resulte um efeito macroscópico de reforço mecânico.

A designação "IPN" (INTERPENETRING POLYMER NETWORK) que poderá traduzir-se por "Polimero de estruturas entrecruzadas", é normalmente aplicada a polímeros com dois ou mais tipos de redes estruturais, em fases não segregadas, e de que resulta em muitos casos um sinergismo de propriedades.

Inicialmente a designação IPN foi aplicada a misturas de polímeros termoendurecíveis reagindo em simultâneo numa mesma fase, no entanto recentemente tem sido aplicada por extensão a termoplásticos em que são induzidas na transformação um número significativo de ligaçðes cruzadas, normalmente por processo radicalar.

\section{Conclusões}

A grande fiabilidade dos processos de transformação de termoplásticos e a versatilidade de propriedades dos termodurecíveis, fazem prever a expansão das Indústrias associadas a um e outro tipo de polímeros.

A utilização de polímeros tem crescido em praticamente todos os tipos de aplicaçōes e notoriamente na substituição de materiais tradicionais.

\footnotetext{
* Assistente Convidado do I.S.T.-U.T.L.

Coordenador de Estudos e Desenvolvimento - Quimigal, Divisão de Plásticoś e Especialidades Químicas.
} 